Method for determining gelatinolytic activity in tissue extracts:

Real-time gelatin zymography

Elin Hadler-Olsen and Jan-Olof Winberg

Department of Medical Biology, Faculty of Health Sciences, UiT-The Arctic University of Norway, 9037 Troms $\varnothing$, Norway.

Corresponding authors email addresses

Elin Hadler-Olsen: elin.hadler-olsen@uit.no

Jan-Olof Winberg: jan.o.winberg@uit.no 


\title{
Method for determining gelatinolytic activity in tissue extracts: Real-time gelatin zymography
}

Elin Hadler-Olsen and Jan-Olof Winberg

Running Head

Real-time gelatin zymography

\begin{abstract}
To explore the physiological or pathological roles of proteases, it is important to be able to detect and precisely localise them in a tissue, to differentiate between inactive and active forms, as well as to quantify and determine the nature of the enzyme that degrade a given substrate. Here we present a protocol for real-time gelatin zymography that is very useful for the detection of gelatin degrading proteases in tissue extracts. This method uses fluorescence labelled gelatin and therefore, we also present an easy, fast and cheap method for labelling gelatin with 2-Methoxy-2,4-Diphenyl-3(2H)-Furanone (MDPF).
\end{abstract}

\section{Key words}

Gelatinase; fluorescence labelling of gelatin; MDPF-gelatin; real-time gelatin zymography; tissue; proteases; matrix metalloproteases; 


\section{Introduction}

Proteases cleave proteins and peptides either at the $\mathrm{N}$ - and $\mathrm{C}$-terminal ends (exopeptidases) or within the polypeptide chain (endopeptidases). These enzymes exist in all living organisms and there is estimated to be more than 66000 different proteases [1, 2]. They are localized either within a cell, on or in the cell membrane, or secreted from the cell into the extracellular space [3]. Proteases are important for an organisms' survival [4, 5]. Dysregulation of one or several proteases in humans and other vertebrates is associated with disease, and proteases are often involved when micro-organisms invade a host $[6,7,8,9]$. Hence, proteases are important targets for therapeutic intervention $[10,11]$.

Proteases are classified into eight different classes/clans based on the amino acid or prosthetic group involved in the catalytic reaction. These classes are aspartic (A), cysteine (C), glutamic $(\mathrm{G})$, metallo $(\mathrm{M})$, aspargine $(\mathrm{N})$, mixed $(\mathrm{P})$, serine $(\mathrm{S})$ and threonine $(\mathrm{T})$ proteases (Merops database) [12].

There are more than 566 human and 644 murine proteases, of which 273/341 are secreted, $277 / 283$ are intracellular and 16/16 are intramembraneous, respectively. The majority of human and murine proteases are of the metallo-, serine- and cysteine type, where most of the metallo- and serine proteases are secreted while the cysteine proteases are mainly localized within the cell [3].

Proteases induce an irreversible change of the substrate they process. Hence, most proteases are tightly regulated at the transcriptional, post-transcriptional, translational and/or the posttranslational level. These enzymes are synthesised in an inactive pro-form, and are either activated within the cell or in the extracellular space. Once activated, their activity is 
regulated by protease inhibitors that bind either reversibly or irreversibly to the enzyme $[6,9$, $13,14]$.

To explore the physiological or pathological roles of proteases, it is important to be able to detect and precisely localise them in a tissue, to differentiate between inactive and active forms, as well as to quantify and determine the nature of the enzyme that degrade a given substrate. Active proteases can be determined in tissue by in situ substrate zymography. Here we will present a protocol for real-time gelatin zymography, which is very useful for the detection of active gelatinases in tissue extracts. There are several proteases that degrade gelatin (denatured collagen), which include the two matrix metalloproteases MMP-2 and MMP-9 [15]. Other enzymes are serine proteases like trypsin, plasmin and matriptase, as well as cysteine proteases such as cathepsin $\mathrm{L}[16,17,18,19]$. In this protocol we focus on proteases that function around a neutral $\mathrm{pH}$, but the protocol can be slightly changed for the detection of proteases with an optimal activity at slightly acidic $\mathrm{pH}$ (see Note 1).

Proteases can be extracted from both unfixed and fixed tissue, but independent of the extraction method, much larger amount of proteins is extracted from unfixed tissue compared to fixed tissue [20]. We have previously extracted proteins from kidney, liver, tongue and heart tissue by mincing it in a tissue homogenizer with steel bullets in various extraction solutions including:

(1) $0.25 \%$ Triton $\mathrm{X}-100(\mathrm{v} / \mathrm{v}), 10 \mathrm{mM} \mathrm{CaCl} 2$ in Milli-Q water

(2) $10 \%$ DMSO (v/v), $10 \mathrm{mM} \mathrm{CaCl}_{2}$ in Milli-Q water

(3) Zymography loading buffer (1x): $0.05 \mathrm{M}$ Tris-HCl, pH 6.8, 10\% glycerol, $2.0 \%$ SDS, $0.05 \%$ bromophenol blue

(4) $1.0 \mathrm{M} \mathrm{NaCl}, 10 \mathrm{mM} \mathrm{CaCl} 2$ in Milli-Q water 
The extracted proteins can be analysed by different methods such as Western-blotting, SDSPAGE along with mass spectrometry or by gelatin SDS-PAGE zymography. The latter method reveals both the activity and the molecular size of the gelatin degrading proteases. For MMPs, this method detects both the inactive pro-form and the active form of the protease because pro-MMPs refold and auto-activate when SDS is washed away after the electrophoresis. During the following incubation period (usually $37^{\circ} \mathrm{C}$ ) proteases can degrade the gelatin incorporated in the SDS-gel. Even though gelatin SDS-PAGE zymography gives information of the gelatin degrading enzymes present in the tissue, most reversible inhibitors will be dissociated from the proteases during SDS-PAGE, and hence, it is not possible to conclude that the proteases detected are active in situ. Therefore, gelatin SDS-PAGE zymography and gelatin in situ zymography are complementary techniques for the characterization of gelatin degrading enzymes in a tissue. For both in situ and SDS-PAGE gelatin zymography, various types of inhibitors can be used to determine the type of protease responsible for the substrate degradation (see Note 2).

When extracting gelatinolytic enzymes from a tissue, other proteins will follow. These nongelatinolytic proteins can overlap and mask the gelatinolytic bands when running an ordinary gelatin SDS-PAGE gel. To avoid this problem, real-time SDS-PAGE zymography can be run instead.

In contrast to normal gelatin zymography, real-time gelatin zymography is based on the use of fluorescence labelled gelatin. Thus, it is not necessary to stain the gel after electrophoresis and hence other proteins in an extract will not interfere with the detection of gelatinolytic proteases. Another advantage is that it is possible to follow the development of gelatin degradation in real-time by observing the gel under UV-light (see Note 3). In this protocol, we will describe an easy, fast and cheap method for labelling gelatin with the dye, 2-Methoxy2,4-Diphenyl-3(2H)-Furanone (MDPF). The dye reacts rapidly with primary amines and form 
highly fluorescent and stable fluorophores $\left(\lambda_{\mathrm{ex}}=385 \mathrm{~nm}\right.$ and $\left.\lambda_{\mathrm{em}}=480 \mathrm{~nm}\right)$, while the unbound dye and its hydrolysis products are non-fluorescent. The concentration of bound MDPF to gelatin can be determined from measuring the absorbance of the labelled gelatin at $385 \mathrm{~nm}$, using the extinction coefficient, $\varepsilon^{385 \mathrm{~nm}} \approx 6500 \mathrm{M}^{-1} \cdot \mathrm{cm}^{-1}$. This protocol is based on MDPF labelling of triple helical collagen [21]. Figure 1 shows a comparison between real-time gelatin zymography using MDPF-labelled gelatin and the traditional normal gelatin zymography. Previously, Hattori et al. has described real-time zymography and real-time reverse zymography using FITC-labelled collagen, casein and BSA [22]. The real-time zymography method presented here using MDPF-labelled gelatin can easily be converted to real-time reverse gelatin zymography by simply incorporate an appropriate amount of an enzyme like MMP-9, MMP-2 or trypsin in the SDS-PAGE gel along with the MDPF-gelatin (see Note 4). We have used this real-time reverse gelatin zymography method in several of our studies to detect the expression of tissue inhibitors of MMPs (TIMPs) [23, 24, 25].

"[Fig 1 near here]"

\section{Materials}

\subsection{Reagents and buffers}

1. Gelatin (type A, porcine skin).

2. 2-Methoxy-2,4-Diphenyl-3(2H)-Furanone (MDPF).

3. Acetone.

4. Acrylamide/Bis-acrylamide (29:1) (40\% solution) (see Note 5).

5. Sodium dodecyl sulfate (SDS) (see Note 6).

6. Bromphenol blue.

7. $\mathrm{N}, \mathrm{N}, \mathrm{N}^{\prime}, \mathrm{N}^{\prime}-$ Tetramethylethylenediamine (TEMED). 
8. $10 \%$ ammonium persulphate (APS) in Milli-Q water (stored at $4{ }^{\circ} \mathrm{C}$ ).

9. Optional: enzyme inhibitors such as ethylenediaminetetraacetic acid (EDTA), Galardin, Pefabloc.

10. $50 \mathrm{mM}$ Sodium tetraborate, $\mathrm{pH} 9.0$.

11. Separating gel buffer: $1.5 \mathrm{M}$ Tris-HCl, $\mathrm{pH} 8.8,0.4 \%$ SDS (see Note 6).

12. Stacking gel buffer: $0.5 \mathrm{M}$ Tris-HCl, $\mathrm{pH}$ 6.8, 0.4\% SDS.

13. Electrophoresis buffer: $25 \mathrm{mM}$ Tris, $190 \mathrm{mM}$ Glycine, $\mathrm{pH}$ 8.3, 0.1\% SDS.

14. Zymography loading buffer (5x): $0.25 \mathrm{M}$ Tris-HCl, pH 6.8, 50\% Glycerol, $10 \%$ SDS, 0.5\% Bromphenol blue (see Note 7).

15. Wash buffer: $2.5 \%$ Triton X-100 in Milli-Q water.

16. Developing buffer: $0.05 \mathrm{M}$ Tris- $\mathrm{HCl}, \mathrm{pH} 7.5,0.2 \mathrm{M} \mathrm{NaCl}, 5 \mathrm{mM} \mathrm{CaCl}_{2}, 0.02 \%$ Brij35.

\subsection{Equipment}

1. Imaging system with a transilluminator (with $302 \mathrm{~nm} \mathrm{UV} \mathrm{or} 365 \mathrm{~nm}$ long wave UV) and a Camera with an emission filter in front of the lens.

2. Heating cabinet $\left(37^{\circ} \mathrm{C}\right)$.

3. Vertical electrophoresis equipment with cooling.

4. Power supply.

5. Gel casting system for polyacrylamide gels, including glass and alumina plates with appropriate spacer and well-combes.

6. Optional: Hand held UV-lamp (we use Model UVL-21, Long wave UV-366 nm; UVP Inc.).

7. Optional: Converting plate with excitation filter converting UV $302 \mathrm{~nm}$ to UV $365 \mathrm{~nm}$ (Ultra-Violet Products LTD) 
8. Optional: Emission filter that transmit light in the region 465-495 nm (Ultra-Violet Products LTD).

\section{Methods}

\subsection{Labelling of gelatin with MDPF}

All solutions and steps containing MDPF should be protected from light.

1. Dissolve $37.5 \mathrm{mg}$ gelatin in $5 \mathrm{~mL} 50 \mathrm{mM}$ sodium tetraborate buffer $\mathrm{pH} 9.0$. Warm the solution until the gelatin is dissolved, and then allow the solution to cool down to room temperature. Use a magnet for stirring. (To label larger amounts of gelatin, see Note 8).

2. Dissolve $2 \mathrm{mg}$ of 2-Methoxy-2,4-Diphenyl-3(2H)-Furanone (MDPF) in $3 \mathrm{~mL}$ of acetone.

3. Add the MDPF solution slowly to the gelatin solution (room temperature; should take about $1 \mathrm{hr}$ ), with continuous stirring. When all MDPF is added, keep on stirring for 1 $\mathrm{hr}$ at room temperature.

4. Dialyse the labelled gelatin against $2 \times 1 \mathrm{~L}$ of Milli-Q water at $4{ }^{\circ} \mathrm{C}$. This is to remove unbound MDPF and buffer.

5. Lyophilize the dialysed MDPF-labelled gelatin (see Note 9).

6. Dissolve the lyophilized MDPF-labelled gelatin in $1.875 \mathrm{~mL}$ Milli-Q water. This gives a gelatin concentration of approximately $2 \%$.

7. Store dark in small batches. For long time storage, use a freezer.

\subsection{Preparation of MDPF-gelatin SDS-PAGE separating gel}


1. The amounts given are for a separating gel with the following dimensions: $(0.75 \mathrm{~mm} \times 8.2$ $\mathrm{cm} x 5.5 \mathrm{~cm}$ ), i.e. a total volume of approximately $4.5 \mathrm{~mL}$ for $7.5 \%, 10 \%$ and $13 \%$ polyacrylamide gels. A $7.5 \%$ gel is ideal for enzymes with a molecular size of $90 \mathrm{kDa}$ or larger, while a $10 \%$ gel is best suited for enzymes with molecular sizes between 40 to $90 \mathrm{kDa}$ and a $13 \%$ gel for enzymes with molecular sizes below $40 \mathrm{kDa}$ (see Note 9).

Solutions

1: Separating gel buffer $(\mathrm{mL})$

2: $2 \%$ MDPF-gelatin $(\mu \mathrm{L})$

3: Milli-Q water $(\mathrm{mL})$

4: $40 \%$ Acrylamide (mL)

5: TEMED $(\mu \mathrm{L})$

6: $10 \%$ APS $(\mu \mathrm{L})$
PAGE $7.5 \%$

1.12

225

2.266

0.874

7.0

15
PAGE $10 \%$

1.12

225

1.974

1.166

7.0

15
PAGE $13 \%$

1.12

225

7.0

15

Mix the compounds in a plastic tube. Once the TEMED and APS have been added, the polymerization starts. Mix carefully and load the solution between the glass and alumina plate in a hand cast polyacrylamide gel casting system. Put gently a thin layer of Milli-Q water at the top of the loaded mixture and allow the acrylamide to polymerize (15-20 min). Protect the polymerizing gel from light!

\subsection{Preparation of SDS-PAGE stacking gel}


1. The amount is for a stacking gel with the following dimensions $(0.75 \mathrm{~mm} \times 8.2 \mathrm{~cm} \times 2.5$ $\mathrm{cm}$ ), i.e. a total volume of approximately $1.5 \mathrm{~mL}$. We give the contents of gels with $4 \%$ and $5 \%$ polyacrylamide.

Solutions

1: Stacking gel buffer $(\mathrm{mL})$

2: Milli-Q water $(\mathrm{mL})$

3: $40 \%$ Acrylamide $(\mu \mathrm{L})$

4: TEMED $(\mu \mathrm{L})$

5: $10 \%$ APS $(\mu \mathrm{L})$
PAGE $4 \%$

0.186

155

8.0
PAGE 5\%

0.186

194

8.0

Remove the water and un-polymerised acrylamide over the separating gel. Mix the compounds in a plastic tube. Once the TEMED and APS have been added, the polymerization starts. Mix carefully and load the solution on top of the SDS-PAGE separating gel. Put a well forming comb on top, between the glass and alumina plate and allow the acrylamide to polymerize (15-20 min). If you also expect to detect gelatinases with molecular sizes larger than $300 \mathrm{kDa}$, include also MDPF-gelatin in the stacking gel (see Note 10). Protect from light.

\subsection{Electrophoresis and visualization}

1. Mount the gel-plates on the electrophoresis apparatus.

2. Fill the lower and upper electrophoresis tray with electrophoresis buffer.

3. Mix $10 \mu \mathrm{L}$ of samples and controls with $2.5 \mu \mathrm{L}$ of loading buffer (5x). Notice, no boiling! 
4. Apply $8 \mu \mathrm{L}$ of the non-heated samples and controls onto the gel.

5. Start the cooling of the electrophoresis apparatus.

6. Make sure that the gel is protected from light!

7. Start the electrophoresis (constant current $20 \mathrm{~mA} / \mathrm{gel}$ ).

8. Stop the electrophoresis when the tracking dye has entered the bottom of the gel.

9. Remove the gel from the apparatus.

10. Remove the gel from the casting plates. Use a spatula.

11. Wash the gel $2 \times 30 \mathrm{~min}$ in $50 \mathrm{~mL}$ Wash buffer (the gel must be protected from light).

12. Add $50 \mathrm{~mL}$ of developing buffer (incubate at $37^{\circ} \mathrm{C}$ in dark).

13. The degradation of gelatin can be visualised and photographed under UV light (366 or $302 \mathrm{~nm}$ ) at appropriate time points. Gelatinases are detected as dark bands against the fluorescent MDPF-gelatin background.

\section{Notes}

1. To detect gelatin degrading enzymes with a low $\mathrm{pH}$ optimum, use an appropriate developing buffer. O'Grady et al [21] showed that the overall spectral pattern and the excitation and emission maxima were the same at $\mathrm{pH}$ 4.0 and 7.5 .

2. Various types of inhibitors can be included in the wash and developing buffers to determine the type of protease responsible for the substrate degradation. For instance, $10 \mathrm{mM}$ EDTA will inhibit metalloproteases, $1 \mu \mathrm{M}$ galardin (Gm6001) matrix metalloproteases and $1 \mathrm{mM}$ Pefabloc serine proteases. In the case of serine proteases, the sample can be incubated for 15 min with $1 \mathrm{mM}$ Pefabloc before the sample is mixed with $5 x$ loading buffer and applied to the gel-well, as this is an irreversible inhibitor. 
3. Ideal is to use a UV-lamp with long range UV (366 nm). However, it is also possible to use a UV-lamp with an excitation wavelength of $302 \mathrm{~nm}$ (see figure 1 in the introduction).

4. To perform real-time reverse gelatin zymography, add an appropriate amount of protease (recombinant, non-recombinant, or cell conditioned medium containing only the gelatin degrading protease of interest) to the separating gel (see method 3.2), and reduce the amount of Milli-Q water accordingly. We have used conditioned medium from PMA stimulated THP-1 cells which contained proMMP-9 (92 kDa) and TIMP-1 (28 kDa) [23, 24, 25]. To allow detection of TIMPs (Mr 20-28 kDa) in samples, it was necessary to perform pre-electrophoresis of the gel before the samples were loaded, in order to remove the TIMP-1 incorporated into the gel.

5. Due to health security reasons, we use a commercial $40 \%$ Acrylamide/Bisacrylamide solution in the preparation of all polyacrylamide gels.

6. Due to health security reasons, we use a commercial $20 \%$ SDS solution in the preparation of all buffers that contain SDS.

7. Due to health security reasons, when we make the zymography loading buffer (5x) we do not weigh the SDS powder, but uses a commercial solution of $20 \%$ SDS and hence it is not possible to use $50 \%$ glycerol. Instead, we use $20 \%$ (w/v) sucrose.

8. For MDPF-labelling of larger amounts of gelatin, adjust the amount of tetraborate buffer to obtain the same concentration of gelatin as step 1 in method 3.1. Increase the amount of MDPF and acetone correspondingly. Also, adjust the volume of Milli-Q water during dialysis. 
9. To use dialysed MDPF-gelatin that has not been lyophilized, measure the volume of the dialysed sample and calculate the concentration of MDPFgelatin. Based on this, use an appropriate volume to obtain a concentration of $0.1 \%$ of MDPF-gelatin in the separating gel.

10. Add $150 \mu \mathrm{L}$ of $2 \%$ MDPF-gelatin and reduce the amount of Milli-Q water accordingly to get $0.2 \%$ of MDPF gelatin in the stacking gel. To avoid a dark zone between the separation and stacking gel due to a reduced amount of MDPF-gelatin, be careful to remove all water and un-polymerised acrylamide over the separating gel before the stacking gel is applied.

\section{Acknowledgments}

We are grateful to Dr. Kristin Andreassen Fenton (Faculty of Health Sciences, Department of Medical Biology, UiT-The Arctic University of Norway, Troms $\varnothing$, Norway) for the gift of kidney and liver homogenates from a BALB/c mouse and senior engineer Eli Berg (Faculty of Health Sciences, Department of Medical Biology, UiT-The Arctic University of Norway, Troms $\emptyset$, Norway) for performing the zymography experiments. We also would thank Rod Wolstenholme (Faculty of Health Sciences, UiT-The Arctic University of Norway, Troms $\varnothing$, Norway) for help with the figure.

\section{References}

1. Artenstein AW, Opal SM (2011) Proprotein convertases in health and disease. N Engl J Med 365:2507-2518 
2. Winberg JO (2012) Matrix Proteinases: biological significance in health and disease. In: Karamanos NK (ed) Extracellular Matrix: Pathobiology and Signaling de Gruyter, Berlin, p 230-238

3. Overall CM, Blobel CP (2007) In search of partners: linking extracellular proteases to substrates. Nat Rev Mol Cell Biol 8:245-257

4. Quiros PM, Langer T, Lopez-Otin C (2015) New roles for mitochondrial proteases in health, ageing and disease. Nat Rev Mol Cell Biol 16:345-359

5. Ricard-Blum S, Vallet SD (2016) Proteases decode the extracellular matrix cryptome. Biochimie 122:300-313

6. Hadler-Olsen E, Fadnes B, Sylte I et al. (2011) Regulation of matrix metalloproteinase activity in health and disease. FEBS J 278:28-45

7. Maeda H (1996) Role of microbial proteases in pathogenesis. Microbiol Immunol 40:685-699

8. Tokito A, Jougasaki M (2016) Matrix Metalloproteinases in Non-Neoplastic Disorders. Int J Mol Sci 17

9. Turk V, Stoka V, Vasiljeva O et al. (2012) Cysteine cathepsins: from structure, function and regulation to new frontiers. Biochim Biophys Acta 1824:68-88

10. Brotz-Oesterhelt H, Sass P (2014) Bacterial caseinolytic proteases as novel targets for antibacterial treatment. Int J Med Microbiol 304:23-30

11. Gialeli C, Theocharis AD, Karamanos NK (2011) Roles of matrix metalloproteinases in cancer progression and their pharmacological targeting. FEBS J 278:16-27

12. Rawlings ND, Barrett AJ, Thomas PD et al. (2018) The MEROPS database of proteolytic enzymes, their substrates and inhibitors in 2017 and a comparison with peptidases in the PANTHER database. Nucleic Acids Res 46:D624-D632 
13. Gaffney J, Solomonov I, Zehorai E et al. (2015) Multilevel regulation of matrix metalloproteinases in tissue homeostasis indicates their molecular specificity in vivo. Matrix Biol 44-46:191-199

14. Overall CM, Lopez-Otin C (2002) Strategies for MMP inhibition in cancer: innovations for the post-trial era. Nat Rev Cancer 2:657-672

15. Malla N, Sjoli S, Winberg JO et al. (2008) Biological and pathobiological functions of gelatinase dimers and complexes. Connect Tissue Res 49:180-184

16. Heussen C, Dowdle EB (1980) Electrophoretic analysis of plasminogen activators in polyacrylamide gels containing sodium dodecyl sulfate and copolymerized substrates. Anal Biochem 102:196-202

17. Lin CY, Anders J, Johnson M et al. (1999) Molecular cloning of cDNA for matriptase, a matrix-degrading serine protease with trypsin-like activity. J Biol Chem 274:1823118236

18. Spens E, Haggstrom L (2005) Protease activity in protein-free NS0 myeloma cell cultures. In Vitro Cell Dev Biol Anim 41:330-336

19. Winberg JO, Gedde-Dahl T (1986) Gelatinase expression in generalized epidermolysis bullosa simplex fibroblasts. J Invest Dermatol 87:326-329

20. Hadler-Olsen E, Kanapathippillai P, Berg E et al. (2010) Gelatin in situ zymography on fixed, paraffin-embedded tissue: zinc and ethanol fixation preserve enzyme activity. J Histochem Cytochem 58:29-39

21. O'grady RL, Nethery A, Hunter N (1984) A fluorescent screening assay for collagenase using collagen labeled with 2-methoxy-2,4-diphenyl-3(2H)-furanone. Anal Biochem 140:490-494

22. Hattori S, Fujisaki H, Kiriyama T et al. (2002) Real-time zymography and reverse zymography: a method for detecting activities of matrix metalloproteinases and their 
inhibitors using FITC-labeled collagen and casein as substrates. Anal Biochem $301: 27-34$

23. Loennechen T, Mathisen B, Hansen J et al. (2003) Colchicine induces membraneassociated activation of matrix metalloproteinase- 2 in osteosarcoma cells in an S100A4-independent manner. Biochem Pharmacol 66:2341-2353

24. Malla N, Berg E, Theocharis AD et al. (2013) In vitro reconstitution of complexes between pro-matrix metalloproteinase- 9 and the proteoglycans serglycin and versican. FEBS J 280:2870-2887

25. Mathisen B, Lindstad RI, Hansen J et al. (2003) S100A4 regulates membrane induced activation of matrix metalloproteinase-2 in osteosarcoma cells. Clin Exp Metastasis 20:701-711 